\title{
Evaluation of Double Mesh Modification of Chevrel's Technique in Management of Midline Incisional Hernia
}

\author{
Hazem Nour, Hany Mohamed, Mohamed Farid \\ Department of General Surgery, Faculty of Medicine, Zzagazig University, Egypt
}

Correspondence to: Dr. Hazem Nour; email: hzm_nr@yahoo.com

Received: 01 October 2019; Revised: 30 January 2020; Accepted: 15 April 2020; Available online: 29 May 2020

\begin{abstract}
Background: Chevrel's technique provides tensionfree repair of midline incisional hernia, but wide skin and subcutaneous dissection increases rate of complications. Here, we evaluate the double mesh modification of Chevrel's technique in midline incisional hernia repair. Methods: 22 patients with midline incisional hernia underwent double mesh modification of Chevrel's technique. After excision of hernial sac with minimal dissection of the skin and subcutaneous tissue, the anterior rectus sheath is incised on both sides to create medial flaps that are sutured to each other. Both recti abdominis muscles were dissected off the posterior rectus sheath, opening the retrorectus space. Prolene mesh was fixed in the retrorectus space with prolene sutures, and tailored to cover the bare area of anterior surface of both recti muscles and fixed to the lateral flaps of the anterior rectus sheath with interrupted
\end{abstract}

prolene sutures. Results: We observed no recurrences, no skin necrosis, two cases of seroma, one case of superficial wound infection and one case of temporary chronic pain. Conclusion: Double mesh modification of Chevrel technique is an efficient method for treatment of midline incisional hernia, with minimal surgical site occurrences.

Keywords: Chevrel technique, Double mesh technique, Midline incisional hernia

Ann Afr Surg. 2021;18(1):18-22

DOI: http://dx.doi.org/10.4314/aas.v18i1.4

Conflicts of Interest: None

Funding: None

(C) 2021 Author. This work is licensed under the Creative Commons Attribution 4.0 International License.

\section{Introduction}

Incisional hernia represents the most frequent late complication of abdominal surgery, occurring in $2-23 \%$ of all laparotomies, representing about $10 \%$ of all abdominal hernias (1-2). This rate increases in the presence of systemic or local risk factors. Not even the laparoscopic approach is free from this event $(0.8-1.2 \%)$ (3-4).

Recurrence rate of incisional hernia is always a serious problem. The introduction of mesh repair, while reducing the recurrence rate to $0-10 \%$, increased wound complications by $3 \%$ to $27 \%$ (5-8). Different techniques with different sites for prosthetic mesh placement exist, such as premusculo-aponeurotic position (onlay and

Chevrel's technique) (4,8-11), retromuscular-prefascial and preperitoneal (Rives technique, Stoppa technique) $(4,8,12-13)$. Intraperitoneal insertion can be done via open or laparoscopic approach $(2,4,6-14)$.

In large hernias, sublay position is frequently used in combination with other repairs such as the (endoscopic) anterior or posterior component separation technique (15-16). These techniques require dissection beyond the lateral border of the rectus muscles, increasing the risk of damage to the perforating epigastric arteries and nerves, wound complications and bulging of the lateral abdominal wall (15-17). 
Chevrel's technique entails dissecting the skin and subcutaneous tissue beyond the lateral border of the anterior rectus sheath, increasing the risk of skin necrosis and seroma formation (15).

Our modification of Chevrel's technique offers tensionfree repair of midline incisional hernia without farlateral dissection of skin and subcutaneous tissue, decreasing the rate of skin necrosis and recurrence.

\section{Methods}

This study is a clinical trial carried out between January 2017 and December 2018 on 22 patients with midline incisional hernia. Hernioplasty was performed using the double mesh modification of Chevrel's technique, and all the procedures were performed by the same group of surgeons.

The objective of this study was to evaluate the efficacy of double mesh modification of Chevrel's technique in treatment of midline incisional hernia. The primary outcome of this study was hernia recurrence (detected by clinical and abdominal wall ultrasound examination), and necrosis of the midline wound edges (detected by clinical examination). Seroma, wound infection, and chronic pain, corsage feeling were considered secondary outcomes. Follow-up was carried out in outpatient clinic visits by a working team member, one week after discharge, after 3 months, and later every 6 months.

Exclusion criteria were American Society of Anesthesiologists (ASA) physical status class 3 and 4, inflammatory bowel disease, urgent settings recurrences and previous abdominal neoplasms with high risk of local recurrence (rectal cancer) and pediatric patients. Written informed consent was obtained from all patients participating in the study. The study was approved by the institutional review board and the ethical committee of our university hospital. Also, the study is registered in clinical trials under identifier number NCT04166201. We report no conflict of interest. All patients received an intravenous antibiotic prophylaxis with subcutaneous administration of fractionated heparin before surgery, when indicated.

\section{Surgical technique}

All patients were operated on with the double mesh modification of Chevrel's technique. The previous scar was excised, next the subcutaneous space was dissected deep into the neck of the hernia but was not wider than $1 \mathrm{~cm}$ from the edges of the defect. The sac was then opened and resected, the defect size was measured, the skin and subcutaneous tissue were dissected off the anterior rectus sheath, allowing only dissection of an anterior rectus sheath flap just sufficient to close the defect without tension (Figure 1).

Next, a bilateral longitudinal incision was made on the anterior surface of the anterior rectus sheath and a medial anterior rectus sheath flap was dissected off the rectus abdominis muscle. Both recti muscles were dissected off the posterior rectus sheath opening the retrorectus space, and each of the medial anterior rectus sheath flaps was sutured to its fellow of the other side with slow absorbed sutures, closing the defect without any tension and reforming the posterior rectus sheath (Figures 2 and 3).

A sizable prolene mesh was fixed with prolene sutures in the retrorectus space spreading between lateral ends of the space, and tunneled up $4 \mathrm{~cm}$ in the retrorectus space far from vertical edges of the defect (Figure 4). The anterior rectus sheath was closed using a prolene mesh tailored to the size of the space between the lateral flaps of both sides and sutured to the edges of the lateral flaps with interrupted non-absorbable sutures (Figure 5). Figure 6 illustrates the whole technique. A suction drain is left in site, subcutaneous tissue is closed with Vicryl $(3 \backslash 0)$, skin is closed with prolene $(3 \backslash 0)$, and drain is removed when the amount of drainage is below $30 \mathrm{~mL} /$ day. All patient data including demographic data, preoperative investigations, operative findings such as defect size, operative time, and follow up data such as early postoperative findings (skin edges viability, wound infection, seroma and early hernia recurrence), and late postoperative findings (late hernia recurrence), were extracted. These data were analyzed using SPSS v22. 

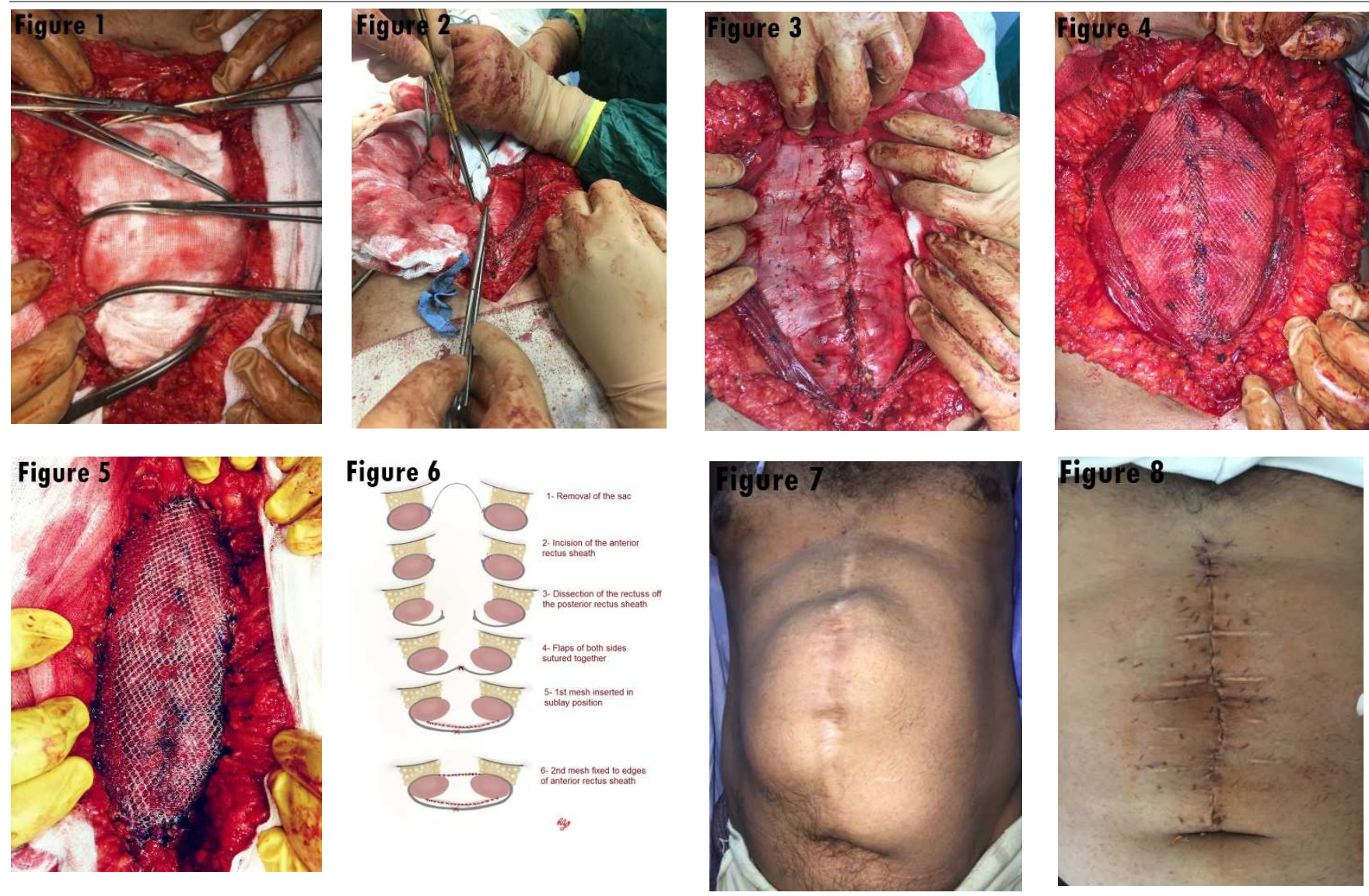

Figure 1: Minimal skin and subcutaneous dissection; Figure 2: Midline closure reformation of the posterior rectus sheath; Figure 3: Reformed posterior rectus sheath; Figure 4: Mesh fixed in retrorectus space; Figure 5: Mesh fixed to flaps of ant rectus sheath; Figure 6: Steps of double mesh modification of Chevrel's technique; Figure 7: Incisional hernia before repair; Figure 8: Incisional hernia after repair.

\section{Results}

This study recruited 22 patients with midline incisional hernia (Figures 7 and 8, before and after repair), who all underwent double mesh modification of Chevrel's technique.

The mean age of patients was $52.36 \pm$ SD 8.7 years, 12 were male and 10 female, and BMI mean $30.1 \pm$ SD 2.8 . Two patients were diabetic and two were receiving anticoagulant therapy. Table 1 presents their demographic data and associated diseases.

The intraoperative findings (defect size and multiple defects encountered during surgery) are in Table 2 . The sizes of defects ranged between $2.5 \mathrm{~cm}$ and $13 \mathrm{~cm}$, the mean diameter was $8.4 \mathrm{~cm} \pm \mathrm{SD}=2.8 \mathrm{~cm}$. Multiple defects were found in 8 patients, dermolipectomy was done on 3 patients, and the operative time ranged between 95 minutes and 140 minutes, with mean time $110.5 \pm$ SD 10.7 .

The follow-up period ranged between 7 and 31 months, with mean follow up time $23.4 \pm 7.8$ months. By this period there was no recurrence or skin necrosis but we encountered seroma in two patients, which resolved within 2 weeks after two times aspiration and suction drain removal. Superficial wound infection occurred in one patient which resolved with conservative measures, while chronic pain occurred in one patient and disappeared after 6 months, and corsage feeling occurred in one patient and disappeared after 5 months (Table 3). 
NOUR ET AL.

Table 1: Demographic data and associated conditions

\begin{tabular}{|c|c|c|}
\hline \multicolumn{2}{|c|}{ Parameter } & Value \\
\hline \multicolumn{2}{|c|}{ Age } & $52.36 \pm$ SD 8.7 \\
\hline \multirow[t]{2}{*}{ Gender } & Male & $12(54.5 \%)$ \\
\hline & Female & $10(45.5 \%)$ \\
\hline \multicolumn{2}{|l|}{ BMI } & $30.1 \pm$ SD 2.8 \\
\hline \multicolumn{2}{|l|}{$\mathrm{DM}$} & $2(9.1 \%)$ \\
\hline \multicolumn{2}{|c|}{ Anticoagulant therapy } & $2(9.1 \%)$ \\
\hline
\end{tabular}

Table 2: Intraoperative findings ( $n=22$ patients)

\begin{tabular}{ll}
\hline Parameter & Value \\
\hline Defect size & $8.4 \mathrm{~cm} \pm \mathrm{SD}=2.8 \mathrm{~cm}$ \\
Multiple defects & $8(36.3 \%)$ \\
Associated surgery & $3(13.6 \%)$ \\
Operative time (min) & $110.5 \pm \mathrm{SD} 10.7$ \\
\hline
\end{tabular}

Table 3: Follow-up data ( $n=22$ patients)

\begin{tabular}{ll}
\hline Parameter & Value \\
\hline Follow up time & $23.4 \pm$ SD 7.8 months \\
Recurrence & 0 \\
Skin necrosis & 0 \\
Seroma & 2 patients $(9.1 \%)$ \\
Wound infection & 1 patient $(4.5 \%)$ \\
Chronic pain & 1 patient $(4.5 \%)$ \\
Corsage feeling & 1 patient $(4.5 \%)$ \\
\hline
\end{tabular}

\section{Discussion}

Incisional hernia may be a very serious and disabling disease. Its treatment is also challenging because improper surgery may imply a high recurrence rate (up to $50 \%$ ), with unacceptable morbidity and mortality $(7,8-9)$.

Chevrel's and onlay techniques were used to repair wide incisional hernias. The two techniques differ in operative details: in Chevrel's technique, the defect is closed with sliding myofascial flaps obtained from incision of the anterior layers of rectus sheaths (18). A common feature of both techniques is placement of the mesh in the onlay position on the fascia (5-19).

Previous studies reported a high wound complication rate after the original Chevrel's technique as well as for the other onlay techniques that include skin necrosis, seroma formation and wound infection, which was attributed to the extensive subcutaneous dissection to facilitate overlap of the mesh beyond the lateral border of the rectus abdominis muscles. (16).

In terms of recurrence, Chevrel's technique achieved a good outcome as the repair carries no tension on the closure of the hernial defect. In this study, we used a double mesh modification of Chevrel's technique in the sublay and onlay positions, with minimal dissection of skin flaps. We obtained good results in the follow-up time, as the rate of seroma formation, superficial wound infection even in the presence of DM or anticoagulant therapy is comparable to the study of Köckerling (19) on Chevrel's technique. Also, the corsage feeling and chronic pain which disappeared after 6 months were close to the results of most related studies.

The most important results achieved through this technique is the zero-recurrence rate in the period of follow-up. This may be due to the augmentation of the newly formed posterior rectus sheath with nonabsorbable mesh in the sublay position together with the onlay mesh sutured to the edges of the anterior rectus sheath covering the dissected surface of the rectus abdominis muscle. This double mesh technique offers tension free repair of the wide incisional hernia defects and avoids the future need to augment the widened, newly formed posterior rectus sheath, as in the study of Mummers et al. (16).

Mladenovikj et al. (20) reported skin necrosis in 4\% of patients. In this study there was no skin flap necrosis; this may be due to the minimal dissection of the skin and subcutaneous tissue from the anterior rectus sheath, thus preserving blood vessels supplying the skin.

\section{Conclusion}

The double mesh modification of Chevrel's technique offers an efficient, tension-free repair with a low complication rate for treatment of midline incisional hernia.

\section{References}

1. Licheri S, Erdas E, Pisano G. Chevrel technique for midline incisional hernia: still an effective procedure. Hernia 2008;12121-6. 
2. Leibl BJ, Schmedt CG, Schwarz J, et al. Laparoscopic surgery complications associated with trocar type design: review of literature and results. J Laparoendosc Adv Surg Tech 1999;9:135-140

3. Loriau J, Manaoinal D, Verhaeghe P. Celioscopie: les éventrations sur orifices de trocarts. Ann Chir. 2002; 252-256.

4. Millikan KW. Incisional hernia repair. Surg Clin North Am 2003; 1223-34.

5. Den Hartog D, Dur AH, Tuinebreijer WE. Open surgical procedures for incisional hernias (review). Cochrane Database Syst Rev. 2008;16:CD006438. Review.

6. LeBlanc KA. Laparoscopic incisional and ventral hernia repair: complications - how to avoid and handle. Hernia. 2004; 8:323331

7. Luijendijk RW, Hop WCJ, van den Tol MP, et al. A comparison of suture repair with mesh repair for incisional hernia. N Engl J Med. 2000;343:392-398.

8. Korenkov M, Paul A, Sauerland S, et al. Classification and surgical treatment of incisional hernias. Results of an experts' meeting. Langenbecks Arch Surg. 2001; 386:65-73.

9. Afify RY. A prospective study between two different techniques for the repair of a large recurrent ventral hernia: a double mesh intraperitoneal repair versus only mesh repair. Hernia. 2005; 9:310-315

10. Chevrel JP, Rath AM. Classification of incisional hernias of the abdominal wall. Hernia. 2000; 4:7-11

11. Langer C, Liersch $\mathrm{T}$, Kley $\mathrm{C}$, et al. Twenty-five years of experience in incisional hernia surgery. A comparative retrospective study of 432 incisional hernia repair. Chirurg. 2003; 74:638-645
12. Notash AY, Farshi JS, Amoli HA, Salimi J, Mamarabadi M. Outcomes of the Rives-Stoppa technique in incisional hernia repair: ten years of experience. Hernia. 2007; 11(1):25-9.

13. Rives J, Lardennois B, Pire JC, Hibon J. Les grandes éventrations. Importance du volet abdominal et des troubles respiratoires qui lui sont secondaires. Chirurgie. 1973; 99:547563.

14. Egea DM, Martinez JT, Cuenca GM, De Miquel J, Lorenzo JM, Albasini JA, Jordana MC. Mortality following laparoscopic ventral hernia repair: lessons from 90 consecutive cases and bibliographical analysis. Hernia. 2004; 8(3):208-12.

15. de Vries Reilingh TS, van Goor H, Rosman $\mathrm{C}$ et al. "Components separation technique" for the repair of large abdominal wall hernias. J Am Coll Surg. 2003; 196:32-37

16. Mommers EH, Wegdam JA, Nienhuijs SW, de Vries Reilingh TS. How to perform the endoscopically assisted components separation technique (ECST) for large ventral hernia repair. Hernia. 2016; 20(3):441-447.

17. De Vries Reilingh TS, van Geldere D, Langenhorst B. Repair of large midline incisional hernias with polypropylene mesh: comparison of three operative techniques. Hernia. 2004;8:5659

18. Chevrel JP, Rath AM. The use of fibrin glues in the surgical treatment of incisional hernias. Hernia. 1997; 1:9-14.

19. Köckerling F. What do we know about the Chevrel technique in ventral incisional hernia repair? Frontiers in Surgery, 2019; 6, Article 15

20. Mladenovikj D, Devaja LA, Tahir S, et al. The Chevrel technique in the treatment of midline giant incisional hernia. Scripta Sci Med. 2016; 48. 